\title{
A literatura entre fronteiras e deslocamentos: corpo, papel e imagem
}

\author{
Alai Garcia Diniz
}

\section{Resumo}

Esse estudo propóe esboçar uma leitura inter-fronteiriça para refletir sobre a literatura transnacional à luz de textos e textualidades de Augusto Roa Bastos. A relação entre a produção roabastiana no exílio portenho; o contato com o que resta da proposta da "nova novela latino-americana" e suas práticas experimentais como roteirista, que supõem uma máquina de ler transgressiva com referência à concepção convencional do que se entende por literatura, incorporando, além do papel, o corpo e a imagem.

Palavras chave: Augusto Roa Bastos; oralidades; imagem; corpo, papel

\section{Resumen}

Ese estudio plantea una lectura interfronteriza para reflexionar sobre la literatura transnacional a la luz de textos y textualidades de Augusto Roa Bastos. La relación entre la producción roabastiana en el exílio porteño, el contato con lo resta de la propuesta de la "nueva novela latinoamericana" y sus prácticas experimentais como guionista suponen una máquina de leer transgresiva a la concepción convencional de lo que se entiende por literatura, al incorporar además del papel, el cuerpo y la imagen.

Temas: Augusto Roa Bastos; oralidades; imagen; cuerpo; papel 
Preâmbulo: O alarde na mídia latino-americana em torno de Gabriel García Márquez e mais especificamente em torno dos 40 anos de Cien Años de Soledad (1967) não deixa de ser um lance de marketing editorial. 0 primeiro livro a ter uma tiragem de 1 milhão de exemplares numa única edição em língua espanhola indica a escala globalizada da mercadoria conhecida como baluarte cultural que é o livro na era do pragmatismo da globalização.

Chama a atenção também o fato de advir de uma produção cultural, oriunda de uma geração de autores do novo romance latino-americano, conhecida popularmente por "boom" e que transformou o espaço da América Latina em parte do imaginário ocidental, com a publicação e tradução de obras, no primeiro mundo. Autores até então pouco conhecidos, como Carlos Fuentes, José Rulfo, mexicanos, Mario Vargas Llosa e José Maria Arguedas, peruanos, José Donoso, chileno, João Guimarães Rosa, brasileiro; Augusto Roa Bastos, paraguaio, e Julio Cortazar, argentino, entre outros. Escritores que acreditaram na utopia do grande relato como parte de uma atividade potencialmente contestadora de regimes ditatoriais que grassavam pela América Latina.

O contexto que tinha, de um lado, a Revolução cubana, e a expectativa sobre o regime de Fidel e o que representaria isso para o resto da América Latina e diferentes interesses econômicos dos países centrais, e, de outro, a Guerra Fria com a política americana de apoio às ditaduras sul-americanas. Os escritores se reuniam, reconheciamse como grupo e escreviam romances como Cien años de Soledad, que agora se reedita em escala global.

Como diz Helinghaus, aqui cabe perceber os nexos entre emancipação e colonização, para abrir outras dimensões de análise dos conflitos e pactos num mundo desigualmente moderno. É preciso indagar sobre a assimetria dos bens culturais, pois o que pode parecer como assimetria em critérios só estéticos e literários, liga-se na prática com esferas que se disseminam, negociam e combatem as matrizes sócio-históricas do desejo e do poder. (HELINGHAUS: 2004, p. 26).

A partir desse preâmbulo que mostra o romance como mercadoria no contexto globalizado, gostaria de compartilhar algumas idéias sobre a modernização latinoamericana, bem como reflexóes sobre conceitos que envolvem o estudo da literatura. Num momento como esse propor redimensionamentos e deslocamentos entre diferentes elos culturais possibilita rever a desgastada polaridade entre oralidade e escritura para vislumbrar a aliança com a desmistificação do livro e da cidade letrada, e a partir da enorme repercussão do melodrama televisivo na América Latina.

Nos anos 80, Roa Bastos testemunhou o abandono da ilusão na capacidade prognóstica das ciências sociais e culturais. Compreendia a despedida de conceitos idealistas no campo da literatura, das artes do contexto popular ou como contracultura política ou utopia, afirmando: La literatura no salvará Latinoamérica. (ROA BASTOS:1984)

A ironia de escritores latino-americanos da atualidade transforma Macondo, a cidade inventada por Gabo, em Mc ondo, e com o trocadilho cria a assimilação dessa cidade invisível à cadeia de fast food e ao que a publicação em escala global simboliza. Mc ondo vira rótulo de apresentação de uma geração crítica ao modelo de Gabo, hoje 
partícipe canônico da literatura ocidental.

Ainda que no hemisfério sul e, portanto, em ambiente repleto de desigualdades e com atraso, a complexidade da revolução eletrônica digital muda hábitos sociais, incide diretamente sobre a cultura local e exige da academia revisão de suportes para atender a novas gerações que transformaram seus hábitos culturais. Segundo Martin Barbero, não foi o livro e sim os meios eletrônicos e as narrativas audiovisuais que trouxeram a modernidade a amplas camadas da população latino-americana, e esse dado exige que, em lugar da primazia do papel, instalem-se hoje a necessidade de ler outras textualidades em diferentes suportes. Com o advento da virtualidade, a rede molda novas concepções de relação humana (a ausência "viva"). Nesse contexto, a presença do corpo e da voz adquirem novos sentidos e percepções, criando um suporte que cava leituras. Aflora então a questão da oralidade como escritura e da escritura como oralidade. A escritura serve para se transformar em voz (oralidade secundária) a ser usada na ima* gem. A imagem integrada no cotidiano entra no arsenal dos estudos literários pela via da necessidade de ler gêneros e bens culturais cada vez mais diversificados. Escritores tornam-se roteiristas e roteiristas escrevem obras literárias.

A história da literatura agrupa textos cronologicamente, segundo as premissas e interesses próprios dos historiógrafos. Como descolonizar a mente?

Uma modernidade heterogênea assinala a necessidade de pensar a literatura a partir da viagem aos corpos, papéis e imagens (Michel de Certeau) e que transporta meios, suportes e se empapa de sentidos complexos. Similar ao conceito de fronteira , como zona de contato cultural, de conflito e intercâmbio ao mesmo tempo, toma-se o conceito de fronteira como busca para pensar com Helinghaus uma nova postura. Em lugar do território estável da subjetividade, a diáspora; em lugar da literatura em lócus da nação o transnacional ou inter-fronteiriço. Nada melhor que um exemplo através de uma incursão ao tópico da gauchesca. Assistir o filme argentino de Adrián Caetano -Un oso rojo (2004), poderia ser o primeiro passo porque dialoga com diferentes produtos culturais e traz em seu bojo o conto de Horacio Quiroga sobre os flamingos, sob forma de intertextualidade, e pode ser analisado como uma mirada neo-gauchesca urbana. A partir do filme (produto atual e vizinho) aproximar-se à cidade letrada, com a fábula de Quiroga e ler não só sua função no âmbito da película, mas propor uma rede de contraposições de que é feita a gauchesca desde uma perspectiva transnacional, com estudos que vão de Simões Lopes Neto a Eduardo Gutierrez e a José Hernández, um dos modos de partir do próximo ao remoto, da tela ao texto e vice-versa. Dos meios aos suportes, de pactos e negociações interculturais entre campo e cidade às genealogias uruguaias dos cielitos do século XIX, tratados simbólicos enlaçam pátrias, penetram desertos, criam guerras, matam índios e desenlaçam gaúchos.

As oralidades definidas no bojo do popular, desprezadas como objetos problemáticos em discursos acadêmicos, com os meios audiovisuais ressuscitam deslocamentos, potencialidades e apropriaçóes para revelar a necessidade do estudo interdisciplinar. A emissão e a recepção no aqui- e- agora da performance conduz ao estudo do meio, da mediação, do ato e da recepção. O leitor da novas linguagens, suportes e representações segue sendo leitor porque a literatura pode tornar-se máquina de ler o mundo.

Segundo a escola filológica alemã, os românticos interessados em acercar-se às tradições históricas buscaram a narrativa popular. Inspirados nas idéias de Giambattista Vico (1668-1744), expostas em Princípios de uma ciência nova relativa à natureza 
comum das nações (1725), seu interesse pela oralidade possui duas raízes:

A linguagem falada (Lingüística Moderna - com Saussure) e a recuperação das idéias de Vico. Com a discussão sobre oralidade de Walter Ong, reconhecem-se características próprias do texto oral, tais como a estrutura de repetiçóes freqüentes; a falta de conexão lógica entre as cenas e o caráter rapsódico da apresentação, aspectos que atendem a uma ordem mnemônica. Entretanto, o estudo de Ong não consegue desarticular a polarização entre a cultura oral ( "primary oral culture") e a cultura letrada (baseada na escrituralidade).

Só a partir de Jacques Derrida, em Da Gramatologia (1967), há a critica da dicotomia falsa entre oralidade e escritura. Sua proposta de desconstruçäo evidencia o combate às polaridades $\mathrm{e}$ ao logocentrismo.

Com o desenvolvimento de tecnologias em meios eletrônicos vinculouse o local ao global e o cidadão se transformou em consumidor. A literatura enfoca objetos híbridos e se diversifica em máquinas de leitura de imagens, corpos e papéis. A oralidade toma conta da escritura e a escritura reivindica o espaço do corpo ou da imagem para se instalar cada vez mais num ambiente virtual. Dentre outras abordagens possíveis, a literatura, no processo cultural de adaptação a novas linguagens, pode ser vista como arte performática, ou seja, de ação, isto é, oral. Nessa recomposição de práticas, a performance toma lugar da mera transmissão silenciosa da leitura e se combina a novos planos e demandas. Segundo Paul Zumthor, a "performance é a ação complexa pela qual a mensagem poética é simultaneamente transmitida e recebida aqui e agora." (ZUMTHOR, 1997, p. 21). Essa afirmação ganha outros sentidos a partir do uso da imagem que registra a performance e a transforma em produto mediatizado que, assim como a escritura, se atualiza na oralidade, a oralidade, como base da performance, torna-a mediatizada com o surgimento da tecnologia em que o olho da câmera e a proposta do plano e do olhar dirige e filtra o momento dramático em imagem. Essa torção contemporânea transforma a escritura, a oralidade, a performance e a atuação e, portanto, o fazer literário e a recepção da obra.

Exemplo disso é o relato de Roa Bastos, "El trueno entre las hojas" - conto até certo ponto realista que se vincula à linhagem socialista pelo teor de denúncia do estado de exploração a que eram submetidos os trabalhadores dos engenhos ${ }^{1} \mathrm{e}$ título de seu livro editado em 1953. Chamo a atenção para o fato de que a condiçāo de exilado de Roa Bastos lhe permitiu a liberdade de criação e (re)significação de seu próprio texto que, como no roteiro para um filme, supõe um trabalho de equipe. O filme configura um novo produto cultural que traz ligeira evocação da narrativa primeira e se destaca na história da filmografia argentina por inaugurar a dupla Armando Bó ( diretor) e Isabel Sarli ( atriz). A hibridez entre o neo-realismo italiano com a convocação de atores não profissionais e o destaque para rituais de uma tribo indígena que não aparece no conto, no contexto argentino, se mescla à influência hollywoodiana com a ascensão do mito Coca Sarli. O exemplo de Roa Bastos há 50 anos atrás só mostra a riqueza da abordagem entre diferentes suportes e pode mostrar como é possivel ler a partir de abordagens específicas diferentes artefatos culturais.

1 Na linha de escritor espanhol que investigou esses temas no Paraguai, Rafael Barrett (1876-1910) com Lo que son los yerbales (1908). 
Em seu primeiro exílio (de 1947 a 1976) em Buenos Aires, apresenta-se como precursor do texto grávido que sempre pode parir outro bem cultural. O conto "El trueno entre las hojas" (1953), através do deslocamento que a re-textualização estabelece, migra como roteiro para o campo da imagem e do cinema.

O filme homônimo de 1958, protagonizado por Isabel Sarli ( Coca Sarli) e dirigido por Armando Bó, mostra-se permeado de diferentes projetos e influências. Não considero adequado tratar o novo produto como adaptação porque hierarquiza os suportes. $O$ filme em questão acaba por tornar-se um item obrigatório de um cinéfilo argentino; pois na historiografia cinematográfica sul-americana, El trueno entre las bojas compõe a hibridez da escola neo-realista italiana (em cenas com não-atores indígenas que se representam e no componente de denúncia social) e a inauguração hollywoodiana com a nudez de Coca Sarli. O rio que no conto continha o mito da ancestralidade e do sagrado transforma-se no filme em fluído fetichista.

Atualmente, a cidade letrada toma consciência de que já não centraliza o poder de definir o gosto, mesmo ao hierarquizar as práticas culturais disseminadas por outros centros de legitimação e mediação, daí advém a re-textualização. Os signos verbais se mesclam a outras linguagens, do script ao corpo e à voz ao palco, em que vibra a música, ritmos e movimentos e gestos e a gramática da luz, da imagem e do som ou em computadores e, desse concurso de códigos, nascem novos gêneros, suportes eletrônicos e leituras intersemióticas. A literatura avança para meios inauditos, objetos insólitos e inclui práticas e sujeitos em diáspora.

Introduzir na literatura o tema da performance serve para estudar o presente na profusão de uma nova camada de trabalhadores informais que resgata o histrionismo, a acrobacia e o malabarismo ou a técnica da mímica nas ruas das principais cidades latino-americanas, como os cómicos ambulantes de Lima ou os cuenteros colombianos.

E inclui a poesia étnica, como a de escritores que reivindicam a oralidade como é o caso de Elicura Chihuailaf, poeta mapuche chileno que em sua obra bilingüe ( en castellano e em mapuzugun) Recado confidencial a los cbilenos se autodenomina um "oralitor" porque realiza a "oralitura":

la palabra sostenida en la memoria, movida por ella, desde el hablar de la fuente que fluye en las comunidades. La palabra escrita no como mero artifício lingüístico ...sino como un compromiso en el presente del Sueño y la Memoria. (CHIHUAILAF, 1999,62).

O conceito de heterogeneidade veiculado por Antonio Cornejo Polar e atualizado por Helinghaus explica não uma mescla nem diversidade, mas a desigualdade do mundo simbólico. Como fenômeno político de desigualdade necessita ser combatido discursivamente. $O$ célebre encontro em Cajamarca entre o conquistador que mostra a bíblia para justificar a submissão do império incaico a suas leis e reis e Atahualpa que reaje após cheirar o objeto livro desconhecido, jogando a bíblia ao chão, mostra, como diz Cornejo Polar, "o triunfo inicial da letra e a primeira derrota da voz".

Essa breve incursão pelo mito de Atahualpa e suas atualizações deve-se não só à intenção de consolidar o conceito de heterogeneidade, cunhado por Cornejo Polar, na tensão colonial entre oralidade e escrita, como para combiná-lo à abordagem lezamiana de uma construção histórica que se utiliza do "logos poético". Nessa reflexão 
sobre deslocamentos e fronteiras da literatura a partir de suportes tais como o corpo e a imagem, abordo também a contribuiçáo de Lezama Lima,o escritor cubano que, em lugar da racionalidade, propóe o logos poético para pensar a analogia, a ressonância e as urdiduras realizadas na dança, no teatro, nas máscaras, na música em uma multiformidade do real. Essas manifestações expressariam "uma visão histórica pelo filtro da imagem". (CHIAMPI, 1988, 24) Neste sentido, ao discorrer sobre a idéia de que é impossível reconstruir a verdade dos fatos, Lezama Lima enriquece a história com a idéia de que, a para criar um processo que leva ao auto-conhecimento, surge:

a atividade metafórica que, por sua vez, se distingue do ato de recordar porque se este se vincula " ao espírito, a memória é como um plasma da alma, é sempre criadora, espermática, pois memorizamos a partir da raiz da espécie. (LEZAMA LIMA, 1988, 59).

Ao aplicar sua reflexão sobre o logos poético como produtor de auto- conhecimento num ensaio sobre a poesia de expressão "crioula", Lezama Lima, através de uma catalogação whitmaniana de imagens, vai tecendo as urdiduras sobre as décimas, vindas do romance hispânico, em busca de fatos miúdos, derivação de folhetim, aconselhadas pela música , na sátira de subterrâneo, mal enraizada na picaresca espanhola, "situado entre o percurso do romance e a intensidade da copla", entoação de cego. Lezama comenta que é na "voz que vai resgatando a linguagem de sua própria pertença." E mostra como o corrido e a gauchesca:

nasceram para ficar, pois têm algo de mineral, do costume e do milagre. Têm algo do silencioso repique da morte no dia e'm que morremos. Mas que até lá nos olbam com olbos vivos e nos solicitam. (LEZAMA LIMA, 1988,140)

$\mathrm{O}$ autor vai definindo o corrido mexicano, gênero épico cantado em quartetos de rima variável, característico na literatura oral mexicana e semelhante ao cordel do Nordeste ou aos desafios e pelejas do Sul (desafios, payadas). Discorre com propriedade e esbanjamento neo-barroco sobre as genealogias da literatura gauchesca que ele conceitua como "expressão crioula", envolvendo-nos, seus leitores, naquela fábula de intertextualidade que só ele sabia criar.

Recupero diferentes contribuições de escritores e críticos sobre a oralidade da América Latina, como parte do acervo verbal, vocal (literário) a ser estudado. Após inúmeras transformações de hábitos, suportes e de práticas culturais, com o advento de meios eletrônicos, podem-se operar enlaces para incluir atores, vozes e bens que durante três séculos de hegemonia do livro se omitiram.

Hoje no jogo o corpo entra como eixo de transversalidades (etnia, classe, idade, gênero), ressaltando leituras sobre como a literatura dispõe a subalternidade em sociedades assimétricas como as que ficam do lado debaixo do Equador.

Como relata Gerd Baumann, o ritual público, em sociedades plurais, servem a minorias tanto como um discurso simbólico como uma consolidação de valores e sentidos internos em uma arena que permite e encoraja múltiplas leituras. (BAUMANN, 1989, 101). Não é o mesmo escrever uma história como dançá-la. Inscrevendo-se em diferente racionalidade, a performance se define como conhecimento e ação que se restauram. (SCHECHNER, 1985). No caso do encontro com o conquistador espanhol ocorreu a morte de Atahualpa no século XVI e, até hoje, há textos ininteligíveis que 
transformam aquele ato efêmero em algo sagrado, envolto em mistério, através da voz do corpo e da performance como resistência à letra que traduz o ritual da dominação sobre uma cultura ágrafa. $\mathrm{O}$ ininteligivel da oralidade em performances andinas atuais supre o sentido no ato de comunhão.

Quanto à imagem, representa a abordagem mais iconoclasta de uma história da literatura porque, hoje, a penetração do melodrama televisivo merece destaque e estudo acadêmico. A telenovela que chega aos lares de mais de $80 \%$ dos brasileiros e representa um dos produtos culturais de maior circulação mundial, congrega na indústria cultural modelos melodramáticos ( parte da literatura dramática), utiliza recursos de planos e enquadramento e tratamento da imagem, domina e redimensiona espaços e retira da escola a centralidade da discussão sobre ética, valores morais, cria novos gêneros e nichos, educa e deseduca e re-significa obras canônicas.

Em tempo de diáspora, o caso de Augusto Roa Bastos ( 1913-2005) merece atenção por criar, do texto à tela e da tela, o texto que pare diferentes bens, nos fins dos anos 50 do século XX, com antecipação de meio século o que acaba predominando no início do século XXI. O vínculo que Roa Bastos manteve com a indústria cinematográfica Argentina, ao dedicar-se ao roteiro em sua etapa de exílio em Buenos Aires, compreende um dado distintivo em sua produção. Nos últimos anos essa tendência se instala como parte da indústria cultural de maneira até mesmo instantânea como é o caso de Rosario Tijeras (2002), romance do colombiano Jorge R. Franco que se torna filme logo após a publicação.

Adepto do realismo urbano, em contraste com a hegemonia de García Márquez e o realismo mágico de 1960, Rosário Tijeras invoca a abjeção com o protagonismo da sicária em corpo feminino. Em formato americano de filme de ação, o filme aborta o que a narrativa apresenta de melhor: o suspense relativo ao narrador intradiegético. No entanto, como objeto elaborado para a tela, Rosário Tijeras ( filme dirigido por Emilio Maillé) transforma uma cena secundária no universo do romance - a peregrinação com o cadáver do morto, irmão da sicária, pela cidade de Medellín - em um detalhamento escandaloso que beira $o$ abjeto. E transforma em imagem a ambigüidade narrativa, uma das tendências da narrativa atual latino-americana que explora a violência pela náusea e o excesso em forma de abjeção, impotência e perplexidade.

Na Espanha, a obra Os fantasmas de Gaya (2007) traz o nome de um roteirista e de um diretor de cinema, e chegou por aqui, em tradução ao português, antes que o filme estreasse, em setembro de 2007. Milos Forman e Jean-Claude Carrière estão ambos reunidos em um filme, lançado no final de 2006, na Espanha. Essa tática da indústria de bens culturais revela que o romance (traduzido por Paulina Wacht e Ari Roitman, em edição da Companhia das Letras) precisa chegar antes ao leitor de elite, com poder aquisitivo para apoderar-se desse bem mercantil: o livro, antecedendo ao filme que atinge a uma camada mais ampla e de menos poder de compra. Este e outros exemplos do campo cultural da literatura servem de base para essa reflexão ainda em processo que tenta contribuir para possíveis diálogos entre suportes (corpo, papel e imagem), imprescindíveis para a crítica literária que pretende ler o mundo tal qual vem se modelando em artefatos culturais que provocam contínuos impasses por suas profanações. 


\section{Referência bibliográfica}

BARTHES, R. - O prazer do texto - trad. J. Guinsburg, SP: Perspectiva,1987.

BAUMANN, G. -" Ritual implicates "Others": rereading Durkheim in a plural society" in COPPET, D. (Editor.) - Understanding Rituals, London and New York: Routledge, 1989.

BOSI, A - Dialética da colonização, São Paulo: Cia das Letras, 1992.

CHIHUAILAF, E. - Recado confidencial a los chilenos. Santiago:Lom, 1999.

CORNEJO POLAR, A - O Condor voa, Belo Horizonte: UFMG, 2001.

HERLINGHAUS, Hermann - Mapas alternativos de la imaginación en Améri-

ca Latina. Madrid: Iberoamericana, 2004

LEZAMA LIMA, J. - A expressão americana, São Paulo: Ed. Brasiliense, 1988

SCHECHNER, R.(1985) -Between Theatre and Antropology, Philadelphia: University Press of Pennsylvania,1995.

ROA BASTOS, A. - El trueno entre las bojas. Buenos Aires: Losada, 1953.

ZUMTHOR, P. - Performance, recepção, leitura. Trad. Jerusa Pires Ferreira e Suely Fenerich. São Paulo:EDUC, 2000. 